\title{
Study on the development of promotional program for college-bound senior students in Taiwan
}

\author{
Lin, Hsiu Fen $\bowtie$ \\ Cultural Worker International Education, Taiwan, ROC (linshowfen@yahoo.com.tw) \\ Lin, Tung Chu \\ College Entrance Examination Center, Taiwan, ROC (tclin@ceec.com.tw)
}

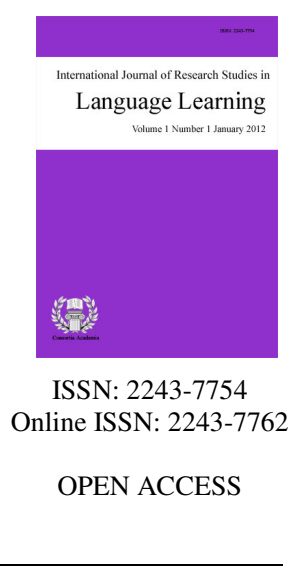

\section{Abstract}

During the initial stage of Taiwan's restoration; National Taiwan University, National Taiwan Normal University, National Chung Hsing University, and National Cheng Kung University implemented joint college recruitment in 1954. As college recruitment and college entrance examination are combined together; the Ministry of Education in cooperation with all other universities established the College Entrance Examination Center in 1989. Since 2011, the Multi-Route Promotion Program (MRPP) for college-bound seniors is developed, wherein two main entry ways are used, namely Admission by Recommendation and Screening and Admission by Examination. Admission by Recommendation and Screening includes the "stars program" and "individual application". For common college entrance examination, subject examinations, such as general scholastic ability test and departmental required test, and practical examinations are included. When handling the examination, examination using information technology and examination for disable individuals are two important aspects for preparation of examination. With regards to the number of disabled examinees who attend subject ability test, it has been increased from three examinees in 1996 to 237 examinees by 2011. Moreover, the strong impact of the trend of fewer children is also a reason for the development of the multi-route recruitment, it is recommended that relevant tasks for preparation of examination should be innovated, core information ability should be established, and examination service should be strengthened.

Keywords: entrance examination; college selection; admission test; English language ability; multi-route admission 


\section{Study on the development of promotional program for college-bound senior students in Taiwan}

\section{Multi-route promotion program (MRPP) for college-bound seniors}

College Entrance Examination Center put forward the Multiple Entrance Policy in 1992, resulting in two revolutions on the ways of college recruitment - the preparation of examination for joint college recruitment would be handled by the colleges themselves again and "recommendation and screening for college admission" has been enforced in 1994 to start multi-route college admission. Later in 1998, "admission by application" has been enforced. After implementing "multi-route promotion program (MRPP) for college-bound seniors" in 2002, the framework of multi-route promotion program has been established firmly (College Entrance Examination Center, 1991, 1998).

"Stars program" was implemented in 2007 to avoid the disadvantages of admission by recommendation and selection and admission by examination and placement that might cause to students with disadvantaged education resources. In "stars program", high schools would recommend students who meet the standard that the college set and the students' performance in high schools would be evaluated to decide on admission; thus, the opportunity of the students from rural area to enter colleges would be promoted relatively. Since stars program showed significant outcome towards the goal of fair and just society and was approved by most of the public, so it is officially a part of multi-route promotion program (MRPP) for college-bound seniors in 2011, including two main admission ways, "admission by recommendation and screening" and "admission by examination". "Admission by recommendation and screening" includes "stars recommendation" and "individual application" (College Entrance Examination Center, 2002a, 2002b). Multi-route promotion program (MRPP) for college-bound seniors was elaborated in the following section.

\subsection{The essence of the program}

The design essence of multi-route promotion program (MRPP) for college-bound seniors aims to avoid considering intellectual education as the single college entrance standard, so that the examinees could assess their own strength, aptitude, ability, and interest so as to select a suitable college entrance way.

\subsection{The structure of the program}

"Admission by recommendation and screening" mainly recruits students according to their qualifications, in which the students should attend general scholastic ability test and meet the requirements and standard of the department of that university. And then, the university departments select students according to their results of general scholastic ability test, practical tests, and examinations in senior high school or these departments would set up second level of screening examination by themselves. For "admission by examination", College Entrance Examination and Placement Committee makes use of computer program to carry out joint placement based on examinees' university priorities and results of general scholastic ability test, department required test, and practical tests.

\subsection{Common entrance examination}

Common entrance examination of multi-route promotion program (MRPP) for college-bound seniors includes subject examinations, such as general scholastic ability test and department required test, and practical examinations 


\subsubsection{Subject Examination}

\section{Table 1}

Comparison of general scholastic ability test and department required test

\begin{tabular}{cll}
\hline Item & \multicolumn{1}{c}{ General scholastic ability test } & Department required test \\
\hline Goal & $\begin{array}{l}\text { Assess whether the examinees possess the } \\
\text { basic scholastic ability and knowledge to } \\
\text { study in universities }\end{array}$ & $\begin{array}{l}\text { Test whether the examinees possess the scholastic } \\
\text { knowledge that the department required }\end{array}$
\end{tabular}

Subject Five subjects include Chinese, English, Mathematics, Social Studies, and Science

Scope Compulsory and elective courses in year one and year two of senior high school

Time Hold during winter vacation; besides the test for Chinese takes 120 minutes, all of the other subjects take 100 minutes.

Question Mainly computer-readable question type type (multiple-choice questions), where Chinese and English have non-multiple-choice questions that needed to be checked manually.

Score $\quad 15$ grade levels

Use Mainly for stars program, individual application, and admission by examination. Also applicable to admission of technical colleges, military and police school, excellent college sports achievement, part-time undergraduate class and colleges in Mainland China and foreign countries.
Ten subjects include Chinese, English, Mathematics A, Mathematics B, History, Geography, Civics \& Social Studies, Physics, Chemistry, and Biology, examinees could select the subjects that they would like to test by themselves (besides examinees who take practical test, at least three subjects must be selected)

Compulsory and elective courses of senior high school

Hold during summer vacation (July 1st to July 3rd); all tests takes 80 minutes.

Includes multiple-choice question (single-choice and multiple-choice) and non-multiple-choice questions; all subjects include non-multiple-choice questions, except Civics \& Social Studies.

100 mark system

Mainly for admission by examination, also applicable to admission of some part-time undergraduate classes.

\subsubsection{Practical Examination}

Three practical examinations, Music, Fine Arts, and Physical Education, are handled by Joint Committee of College Admission Practical Examinations, where Dancing, Drama, Chinese Music, Chinese Opera, and Sports and Athletics are handled by relevant departments.

\subsection{Relationship of examination and admission}

In accordance with the principles of "separation of examination and admission" and "one examination with multi-uses", multi-route promotion program (MRPP) for college-bound seniors makes use of significant common entrance examination together with the examination set by the colleges and results and performance in senior high school to simplify the process of preparation of examination, in which Committee of Recommendation and Screening and Committee of Placement are responsible for relevant recruitment of admission by recommendation and screening and admission by examination respectively. 


\subsection{Enrollment statistics}

\subsubsection{Number of colleges}

Currently, there are 176 colleges in Taiwan, including general colleges and universities, institutes of technology, open universities, vocational schools, and police and military schools. In addition, there are 71 normal universities and colleges of physical education (Ministry of Education, 2010).

\subsubsection{Enrollment and proportion}

In 2011, 113,187 students are actually admitted to universities and colleges, in which 66,683 students (about $58.91 \%$ ) entered the universities and colleges through admission by examination and placement; 34,247 students (about $30.26 \% \%$ ) entered the universities and colleges through admission by recommendation and screening; 6,790 students (about 6\%) entered the universities and colleges through stars program; 5,467 students (about $4.83 \%$ ) entered the universities and colleges through single enrollment, recommendation, or specific placement test (Ministry of Education, 2010).

Table 2

Statistical table of the number of students designated in general universities and colleges

\begin{tabular}{lccccc}
\hline \multicolumn{1}{c}{ Items } & $\begin{array}{c}\text { Stars } \\
\text { Program }\end{array}$ & $\begin{array}{c}\text { Individual } \\
\text { application }\end{array}$ & $\begin{array}{c}\text { Admission by } \\
\text { examination }\end{array}$ & Other ways & $\begin{array}{c}\text { Total number of } \\
\text { students designated }\end{array}$ \\
\hline Ratified number & 7,649 & 40,402 & 56,208 & 10,680 & 114,939 \\
Enrollment Proportion & $6.65 \%$ & $35.15 \%$ & $48.90 \%$ & $9.29 \%$ & 113,187 \\
Number of enrollees & 6,790 & 34,247 & 66,683 & 5,467 & $4.83 \%$ \\
Proportion of enrollees & $6.00 \%$ & $30.26 \%$ & $58.91 \%$ & \\
\hline
\end{tabular}

Note: The number of enrollees that are admitted through ways other than admission by examination would be less than the ratified enrollment number due to insufficient enrollment number, and these enrollees would then be sent back for admission by examination.

\section{Professional Preparation of Examination}

Since College Entrance Examination Center establishes general scholastic ability test in 1994, it carries out all kinds of preparation for examination and changes. The following only discusses two preparations for examination, "informational preparation for examination" and "examination for disability" briefly.

\subsection{Informational preparation for examination}

\subsubsection{Registration}

Since 1996, group registration software is provided and the group registration unit builds e-file of candidate's data. Later in 1997, photo scanning is developed, in which the photo that the candidate uses would be scanned and saved as electronic photo file; this was the first time that the registration card was printed using computer in Taiwan. By 2003, online registration has been developed fully which is the first organization that applies online registration in Taiwan. Online registration not only greatly shortens the time for registration and other relevant tasks, but also reduces a large number of administrative paperwork.

\subsubsection{Optical scoring card}

In 1994, College Entrance Examination Center introduced the first new type of optical reading equipment that is used for reading the answer card of multiple-choice questions, where the answer card is about the size of A5. This answer card is used by other entrance tests, national tests, and senior high school tests in Mainland China as well. Since Mathematics in general scholastic ability test in 1997, the fill-in-the-blank questions have been changed to computer readable multiple-choice questions. Since 2010, the reading model of computer 
readable question type has been designed and developed, namely the answer card would only need to be read once and the original image of this answer card could be scanned and saved, so as to promote the accuracy of reading answer card.

\subsubsection{Test evaluator using computer monitors}

Since general scholastic ability test is carried out in 1994, the answer sheets collected from every examination hall would be covered and bound after the end of every examination to complete the seal function, where this act was learned from Korea. In 1998, "computer-assisted manual test evaluator experimental program" has been established, after going through several actual applications and verifications, strengthening image definition, and introducing e-signature mechanism, this program has been officially used in test evaluator of Chemistry of department required test in 2006. Until 2011, test evaluator using computer monitors has been adopted for answer sheets of all the subjects' in general scholastic ability test and department required test.

\subsection{Examination for disabled examinees}

The ways for students with disability to enter university include "college admission by recommendation and screening for students with disability" and "admission by examination or admission by recommendation and screening of general universities and colleges".

\subsubsection{Recommendation and screening for students with disability}

Recommendation and screening for students with disability was established based on "recommendation system of college admission for blind and deaf students" set in 1963, and it has been revised several times. Its targeted students have been expanded from visually-impaired and hearing-impaired students to students with other disability. According to the data of 2011, 131 colleges and universities provide 2,095 departments with 3,668 students allowed, and 1.852 students signed up in total. For university (not including vocational school), 1,201 students would be expected to enroll, where 718 students signed up.

\subsubsection{Final exams for disable examinees}

In 1989, "assist disabled examinees to take tests on the ground floor" was stipulated in general regulations. Examination hall for disabled examinees has been established in 1993. Later in 1994, "examination for severely disabled examinees" was revised and augmented in general regulations; this is the first regulation that officially proclaimed and stipulated the examination service for disabled examinees in writing in Taiwan. In 1996, "preparation of examination for blind examinees" was stipulated to consider blind examinees as the targeted service group, where special services such as Braille examination questions, sound recording examination questions, and answer using Braille were provided. In 1997, sound recording examination questions with assistance of reporter has been provided for blind examinees, so that the blind examinees could answer with Braille; and then, the scores of the contents of examination questions would be distributed and the result would be calculated.

The number of disabled examinees that are accepted in general scholastic ability test has been increased from three examinees in 1996 to 237 examinees in 2011 substantially; while the proportion of disabled examinees to all examinees has also increased from $0.01 \%$ to $0.16 \%$. College Entrance Examination Center even formed a committee to examine the disability type and level of individual examinees so as to set extended examination time and specific services. In particular, electronic examination questions and sound playing examination questions for the blind that have been implemented in 2007 and 2009 were exhilarating.

\subsubsection{Printing of special examination questions}

For general scholastic ability test in 2011 , for example, not only 860,000 copies of common examination question paper for general examinees were printed, but also special examination questions such as Braille 
Lin, H. F. \& Lin, T. C.

examination questions, electronic examination questions for the blind, and sound playing examination questions were needed to be prepared in different fashions, or even two or more examination questions were needed in the same subject (as shown in Table 3); thus, the complexity of examination question paper printing has been greatly increased. In addition, all of these printings were done within seven to eight working days.

Table 3

Statistic Table for the number of disable examinees who took the tests with special examination question papers in general scholastic ability test from 2002 to 2011

\begin{tabular}{lcccccccccc}
\hline \multicolumn{1}{c}{ Academic Year } & 2002 & 2003 & 2004 & 2005 & 2006 & 2007 & 2008 & 2009 & 2010 & 2011 \\
\hline $\begin{array}{l}\text { A3 enlarged examination } \\
\text { question paper }\end{array}$ & 21 & 36 & 38 & 57 & 49 & 52 & 68 & 48 & 49 & 61 \\
$\begin{array}{l}\text { Braille examination question } \\
\text { paper }\end{array}$ & 11 & 12 & 20 & 13 & 13 & 14 & 12 & 6 & 10 & 15 \\
$\begin{array}{l}\text { Examination questions read by } \\
\text { assistant }\end{array}$ & - & 2 & 0 & 3 & 1 & 5 & 8 & 0 & 0 & 0 \\
$\begin{array}{l}\text { Sound playing examination } \\
\text { questions (Braille) }\end{array}$ & - & - & - & - & - & - & - & 2 & 3 & 2 \\
$\begin{array}{l}\text { Sound playing examination } \\
\text { questions (written words) }\end{array}$ & - & - & - & - & - & - & - & 3 & 3 & 9 \\
$\begin{array}{l}\text { Sound playing examination } \\
\text { questions (picture and written } \\
\text { words) }\end{array}$ & - & - & - & - & - & - & - & - & - & 2 \\
$\begin{array}{l}\text { Electronic examination } \\
\text { questions for the blind }\end{array}$ & - & - & - & - & - & 4 & 4 & 2 & 5 & 7 \\
\hline
\end{tabular}

\section{Conclusion}

\subsection{Retrospect and challenges}

\subsubsection{Strong impact of fewer children}

According to the statistical data that Ministry of Education announced, it is estimated that the number of new student enrollment in junior high school would be decreased from 271,085 students in 2011 to 161,888 students in 2026 substantially, namely 11 thousand students less. This trend of fewer children would definitely influence the demand and supply relationship of number of examinees and number of recruitment. The following impacts would be caused:

\section{Insufficient number of students}

The total recruitment number of universities, colleges, junior colleges, and institute of technology is over 300,000 students, but the graduates of senior high school and vocational school were only 250,000 students; thus, more and more universities and colleges could not enroll enough students because of the rapid decease of number of examinees, this phenomenon would be worsened continuously in the future.

\section{Differences of quality}

A few universities lower the subject requirements or even do not have any requirements pessimistically because of not enough students, but some universities change their strategies of enrolling new students comprehensively and develop teaching goals with stronger department characteristics. Comparatively, in the environment with non-strict enrollment competition, more and more students get rid of the traditional learning 
fetters and explore their personal characteristics in their future university life.

\subsubsection{Development trend of multi-route promotion program}

To cooperate with the promotion of twelve-year basic education program in Taiwan and the society with fewer children, College Entrance Examination Center has proposed all kinds of ideas for program improvement continually since 2009, including loosen restrictions of recommendation and screening ratio year by year, encourage every university to participate actively in "Stars program". For the universities with insufficient students, they are allowed to enroll new students alone with conditions. In recent years, the enrollment number of admission by recommendation and screening of every university has been increased significantly year by year. In 2012, the ratio of enrollment by recommendation and screening of four universities, National Tsing Hua University, National Chiao Tung University, Taipei Medical University, and China Medical University, would be extended to 70\%; this act would definitely influence teaching activities of senior high school and registration for an examination of students. Whether the test scope could cover the courses in senior high school effectively or not, this has to be followed continually.

Admission by recommendation and screening emphasizes the respect of diverse intellect so as to select the students appropriately. How to arrange the preparation of enrollment and examination, not increasing the social cost, and not causing burden to the examinees and parents are the issues that needed to be faces as soon as possible. College Entrance Examination Center held English listening test for senior high school in September 2011 for the first time, and this test would be studied and improved continually thereafter, hoping to obtain approval from universities and trust from the society as soon as possible, so that the test result could be used by all universities officially.

\subsubsection{Active protection of personal rights and interests}

\section{Protection of examination rights and interests}

For preparation of examination, continuous study, discussion, and improvement are needed so that every examinee could show their ability under fair principle and reasonable foundation, for example, setting examination hall in many places so that all students can take examination nearby, children from low-income families do not need to pay for application fee to reduce their economical pressure, setting up online registration for individual application and examines could pay at all convenience stores so that students from remote areas could apply more easily, air-conditioning is provided in the examination halls for department required test to reduce the influence of weather, and providing more individualized and comprehensive examination participation service for disabled examinees to ensure their rights and interests to take the test. Besides performing all kinds of preparation for examination, College Entrance Examination Center should focus on the examinee's rights and interests that the society pays close attention to and request opinions from relevant units and representatives from all circles continuously.

\section{Protection of individual privacy}

As the application of computer becomes more and more popular, "privacy right of information" and "protection of personal information" become more important. The personal information of the examinee that College Entrance Examination Center obtained should be bound by the standard of personal data protection, in which the purpose and target when using examinee's information must be stated in the general regulations of examination clearly. Moreover, the standard of personal data protection must be obeyed when handling all kinds of preparation for examination and sending and using the test results. The personal information of the examinees must not be misused and must be protected actively, preventing the violation of examinee's personal information because of negligence or purposely leakage, so as to ensure the personal privacy of examinees. 


\section{Suggestions}

\subsection{Innovation of preparation of examination}

All regulations and procedures of preparation of examination should be designed systematically in accordance with the fair, just, and open principles of preparation for examination, so as to lower the cost of preparation of examination and promote administrative efficiency. Moreover, cycle model including planning, implementation, review, and action is used to carry out the standardized procedures with the goal of zero drawbacks. As a result, College Entrance Examination Center would become a professional examination organization with credibility.

\subsection{Establish core information ability}

College Entrance Examination Center currently carries out e-administration comprehensively, applies for ISO9001 quality management authentication, expands such information system security authentication as ISO27001, and improves such facilities as information system for preparation of examination, so as to meet the requirement of international information security standard and promote the quality and safety of preparation of examination effectively. In the future, College Entrance Examination Center should further study and develop the fashions of tests and scales, using advanced information technology to strengthen the connection among examinees, senior high schools, and universities.

\subsection{Strengthen relevant examination services}

College Entrance Examination Center has the concept of "examination designated for education service", so it should strengthen the function of information service system continuously and the contents of "e-paper for student selection", in order to expand the scope and depth of examination service and provide interest scales and university department exploration scales to assist the students to find suitable university departments. College Entrance Examination Center should make use of all kinds of database to provide references for senior high schools and university students. Thus, the promotion of preparation for examination that College Entrance Examination Center is engaged in could be changed and improved with each passing day.

\section{References:}

College Entrance Examination Center. (1991). Student admission by recommendation [In Chinese]. Taipei: College Entrance Examination Center.

College Entrance Examination Center. (1998). Tracking and investigation report on the admission by recommendation [In Chinese]. Taipei: College Entrance Examination Center.

College Entrance Examination Center. (2002a). Assessment report on the admission by recommendation and admission by application [In Chinese]. Taipei: College Entrance Examination Center.

College Entrance Examination Center. (2002b). Final report on the review and improvement of the Multi-Route Promotional Program (MRPP) for college bound seniors [In Chinese]. Taipei: College Entrance Examination Center

Ministry of Education. (2010). Summary of statistics. Retrieved June 5, 2011, from http://english.moe.gov.tw/lp.asp?CtNode $=1184 \&$ CtUnit $=415 \&$ BaseDSD $=7 \& m p=2$ 